ARTIGO

\title{
Modelagem matemática na perspectiva da educação matemática crítica: abordagens na educação básica
}

\author{
Milene Nagila Mesquital \\ Amauri Jersi Ceolim \\ (D) \\ Rosefran Adriano Gonçales Cibotto' (D)
}

\section{RESUMO}

Este artigo apresenta alguns resultados de uma pesquisa cujo objetivo foi investigar percepções de professores participantes do Programa de Desenvolvimento Educacional (PDE) sobre atividades de Modelagem Matemática (MM), na perspectiva da Educação Matemática Crítica (EMC), na Educação Básica (EB). Foram investigados trabalhos publicados na página do $\mathrm{PDE}$, sob a orientação de docentes da Universidade Estadual do Paraná (Unespar), campus de Campo Mourão. Os pressupostos teóricos foram baseados em Ole Skovsmose - EMC e alguns autores que abordam a MM no âmbito da EB. O emprego da Análise Textual Discursiva, sugerida por Roque de Moraes, possibilitou a construção de duas categorias que evidenciaram contribuições das atividades de MM para o ensino e a aprendizagem de matemática. Uma contempla o planejamento, a implementação e a avaliação das atividades de $\mathrm{MM}$ na EB, a outra evidencia a preocupação docente com a formação do senso crítico.

\section{PALAVRAS-CHAVE}

educação matemática crítica; modelagem matemática; Programa de Desenvolvimento Educacional; transformação social.

'Universidade Estadual do Paraná, Campo Mourão, PR, Brasil. 


\title{
MATHEMATICAL MODELING IN THE PERSPECTIVE OF CRITICAL MATHEMATICS EDUCATION: APPROACHES IN BASIC EDUCATION
}

\begin{abstract}
The present article presents some results of research, whose objective was to investigate the attending teachers' perceptions in the Educational Development Program (EDP) about activities of Mathematical Modeling (MM) in the perspective of Critical Mathematics Education (CME) in Basic Education (BE). Papers published at the EDP's website under the supervision of professors from Universidade Estadual do Paraná (Unespar), campus Campo Mourão, were investigated. The theoretical assumptions were based on studies by Ole Skovsmose - CME and some authors who approach MM in the scope of BE. The use of Textual Discursive Analysis, suggested by Roque de Moraes, enabled the construction of two categories that evidenced contributions from MM activities to the teaching and learning of Mathematics. One contemplates the planning, implementation, and evaluation of $\mathrm{MM}$ activities in $\mathrm{BE}$; whereas the other highlights professors' concerns about the construction of critical sense.
\end{abstract}

\section{KEYWORDS}

critical mathematical education; mathematical modeling; Educational Development Program; social transformation.

\section{MODELAJE MATEMÁTICO EN LA PERSPECTIVA DE LA EDUCACIÓN MATEMÁTICA CRÍTICA: ENFOQUES EN LA EDUCACIÓN BÁSICA}

\section{RESUMEN}

Este artículo presenta algunos resultados de una investigación cuyo objetivo era investigar las percepciones de los maestros que participan en las actividades del Programa de Desarrollo Educativo (PDE) sobre Modelaje Matemático (MM) en la perspectiva de la Educación Matemática Crítica (EMC) en Educación Básica (EB). Fueron investigados estudios publicados en la página PDE, bajo la orientación de los profesores de la Universidade Estadual do Paraná (Unespar), campus de Campo Mourão. Los supuestos teóricos se basaron en Ole Skovsmose - EMC y algunos autores que se acercan a MM dentro del alcance de EB. El uso del análisis discursivo textual, sugerido por Roque de Moraes, permitió la construcción de dos categorías que evidenciaron contribuciones de las actividades de MM en lo enseñanza y aprendizaje de las matemáticas. Una contempla la planificación, implementación y evaluación de las actividades de MM en EB, y la otra destaca la preocupación de la enseñanza con la formación de un sentido crítico.

\section{PALABRAS CLAVE}

educación matemática crítica; modelaje matemático; Programa de Desarrollo Educativo; transformación social. 


\section{INTRODUÇÃO}

A pesquisa de cunho qualitativo desenvolvida neste trabalho se caracterizou em virtude da preocupação observada no campo investigativo da Educação Matemática (EM) em abordar, por meio da Modelagem Matemática (MM), atividades na Educação Básica (EB) que objetivam, além do desenvolvimento do conhecimento matemático, o desenvolvimento do pensamento crítico dos estudantes. Discussões e reflexões expostas por autores brasileiros que abordam a MM no âmbito da EB, como Meyer, Caldeira e Malheiros (2011), Barbosa (2001; 2004) e Araújo (2009), em que a contemplam à luz de teorias como a da Educação Matemática Crítica (EMC) como concebida pelo professor dinamarquês Ole Skovsmose, nos instigaram a investigar alguns dos aspectos que envolveram atividades de $\mathrm{MM}$, nessa perspectiva, implementadas por docentes da $\mathrm{EB}$ em processo de especialização na carreira do magistério estadual.

Nesse cenário, nos mobilizamos a partir da seguinte questão de pesquisa: quais os reflexos da abordagem de atividades de MM desenvolvidas na perspectiva da EMC na EB, por professores que participaram do Programa de Desenvolvimento Educacional (PDE) ${ }^{1}$ ?

Para o desenvolvimento da análise da pesquisa, foi feito levantamento dos trabalhos de MM desenvolvidos por meio do PDE e realizados sob a orientação de professores da Universidade Estadual do Paraná (Unespar) de Campo Mourão, desde o ano de 2007, quando foi implantado o programa no estado do Paraná.

Os materiais que compuseram o corpus ${ }^{2}$ da pesquisa foram investigados no site da Secretaria da Educação do Estado do Paraná, no qual constam todos os trabalhos desenvolvidos pelos professores participantes do PDE. Todos esses trabalhos são incorporados nos chamados Cadernos $P D E^{3}$, disponíveis no respectivo site.

Foram investigados os trabalhos publicados nos Cadernos PDE entre os anos de 2007 e 2018, dos quais 30 se referem à MM de modo geral e, desses, oito na perspectiva da EMC e 14 em outras perspectivas, como a sociocrítica. Todos esses trabalhos foram considerados para a análise desta pesquisa por contemplarem diversos aspectos relacionados à perspectiva da EMC.

Como pressupostos teóricos, foram utilizadas publicações de Skovsmose (1992, 2000, 2001, 2008, 2017) acerca da EMC, algumas obras de Freire (1987, 2011), assim como concepções de alguns autores brasileiros que abordam a MM no âmbito da EB.

Quanto ao desenvolvimento metodológico da análise da pesquisa, seguiu-se a metodologia da análise textual discursiva de Moraes (2003), que

1 Para mais informações sobre o PDE, acesse o site da Secretaria da Educação do Estado do Paraná, disponível em: http://www.gestaoescolar.diaadia.pr.gov.br/modules/conteudo/conteudo.php?conteudo=20. Acesso em: 9 mar. 2020.

2 Mais detalhes referentes à metodologia estão dispostos na seção específica.

3 Os Cadernos PDE contêm todas as produções dos docentes participantes do programa, que estão disponíveis em: http://www.gestaoescolar.diaadia.pr.gov.br/modules/conteudo/conteudo.php?conteudo=616. Acesso em: 9 mar. 2020. 
consiste em três etapas caracterizadas pelos processos de unitarização, de categorização e de comunicação.

Como resultados das análises da pesquisa, obtiveram-se duas categorias: planejamento, implementação e avaliação das atividades de Modelagem Matemática; e preocupação com a formação do senso crítico, que são acompanhadas dos seus textos explicativos contendo as discussões das análises permeadas pelas concepções dos autores mencionados.

\section{MODELAGEM MATEMÁTICA NA PERSPECTIVA DA EDUCAÇÃO MATEMÁTICA CRÍTICA}

No campo da Modelagem, foram abordadas concepções de alguns pesquisadores brasileiros, tais como: Jonei Cerqueira Barbosa, Ademir Donizete Caldeira e Jussara de Loiola Araújo. Esses autores foram selecionados devido ao fato de terem trabalhos de MM publicados nos anais do $11^{\circ}$ International Congress on Mathematical Education (ICME 2008) (Ceolim e Caldeira, 2013).

A forma como Barbosa (2004) concebe a MM explicita a preocupação do autor em oportunizar aos estudantes indagar diferentes situações reais por meio da matemática. Para o autor, atividades de MM oferecem "condições que propiciam determinadas ações e discussões singulares, em relação a outros ambientes de aprendizagem" (Barbosa, 2004, p. 76). No ambiente de MM, os estudantes são convidados a investigar essas situações reais com o intuito de compreendê-las, problematizá-las e de propor soluções a elas, utilizando-se de seus conhecimentos matemáticos prévios e, ao mesmo tempo, aprendendo novos conceitos e conteúdos matemáticos.

Com base em trabalhos do professor dinamarquês Ole Skovsmose, Barbosa (2001) compreende que o termo ambiente se refere a um lugar ou espaço que cerca e envolve. Para o autor, o "ensino tradicional é um ambiente de aprendizagem, pois estimula os alunos a desenvolverem certas atividades" (Barbosa, 2001, p. 6). Já a MM proporciona um ambiente de aprendizagem que "estimula os alunos a investigarem situações de outras áreas que não a matemática por meio da matemática" (Barbosa, 2001, p. 6).

Meyer, Caldeira e Malheiros (2011) salientam que a MM é trabalhada por um caminho inverso, em que, "ao invés de se dar uma pergunta para o aluno, em que ele vai ter de usar predeterminada ferramenta matemática para garantir a obtenção da resposta certa, o aluno faz a pergunta para si e para os outros" (Meyer, Caldeira e Malheiros, 2011, p. 35). Portanto, não são previamente fixados os procedimentos que serão necessários para a resolução dos problemas abordados em atividades de MM, pois os conteúdos e os conceitos matemáticos vão surgindo conforme as questões são formuladas pelos estudantes.

Skovsmose (2001, p. 127) destaca que os "resultados matemáticos e estatísticos são uma referência constante durante debates na sociedade". Corroborando essa constatação, Araújo (2009, p. 59) manifesta sua preocupação "com uma formação política dos estudantes, de tal forma que eles atuem criti- 
camente em nossa sociedade na qual a presença da matemática é forte”. Pode ser verificado, em jornais e nas mídias de informação, que as questões relacionadas à economia, à política e à tecnologia, por diversas vezes, têm respaldo em resultados matemáticos e as decisões geralmente são tomadas com base nesses resultados, "sugerindo que a decisão tomada aponta o melhor caminho a ser seguido, sem deixar margens para contra argumentações" (Araújo, 2009, p. 63). Nesse tipo de argumentação a matemática é utilizada, em alguns casos, como "parte da linguagem do poder" (Skovsmose, 2001, p. 127), pois é comum que sugestões e decisões do âmbito político, tecnológico e administrativo sejam fundamentadas matematicamente.

A matemática utilizada nesse sentindo pode ser caracterizada, conforme destacado por Skovsmose (2001), como ideologia da certeza, a qual atribui à matemática uma qualificação de poder, de modo que quaisquer argumentos respaldados na matemática são tidos como verdades incontestáveis e como argumentos definitivos.

No entanto, no contexto aqui utilizado, corroboramos o entendimento de Skovsmose (2017, p. 34) relacionado à matemática, no qual evidencia que "para a Educação Matemática Crítica, é importante abordar criticamente qualquer forma de leitura e escrita com a matemática". Coerentemente, a abordagem crítica deve ser feita de maneira que os estudantes possam discutir entre si e refletir acerca dos aspectos qualitativos que permeiam os problemas investigados, desenvolvendo, além do conhecimento conceitual matemático, a compreensão do papel sociocultural da matemática. Assim, a partir das análises e da compreensão de problemas reais da sociedade, que eles possam desenvolver, por exemplo, algumas capacidades, como refletir sobre questões socioeconômicas, políticas, ambientais e culturais, bem como sobre as políticas governamentais criadas e implementadas no âmbito dessas questões.

Para Barbosa (2004, p. 75), a concepção de MM "pode potencializar a intervenção das pessoas nos debates e nas tomadas de decisões sociais que envolvem aplicações da matemática, o que me parece ser uma contribuição para alargar as possibilidades de construção e consolidação de sociedades democráticas".

Para que ocorram essas potencialidades, o processo educacional necessita ser constantemente discutido, vislumbrando sempre novas possibilidades, pois "a educação deve fazer parte de um processo de democratização [...], o processo educacional deve ser entendido como um diálogo" (Skovsmose, 2001, p. 18), porque ensinar não é transferir conhecimento.

Conforme argumenta Freire (1987), ensinar não é encher os estudantes de conteúdo, depositando o que ele chama de comunicados, que são falsos saberes. Falsos porque os estudantes teoricamente fingem que aprendem dessa forma. Para Freire (2011, p. 47), "ensinar não é transferir conhecimento, mas criar as possibilidades para a sua própria produção ou a sua construção". Nessa direção, o autor destaca que, ao entrar na sala de aula, o professor deve estar aberto às indagações, às curiosidades e aos questionamentos dos discentes. Convergindo aos aspectos da EMC, Barbosa (2001) ressalta: 
As atividades de Modelagem são consideradas como oportunidades para explorar os papéis que a matemática desenvolve na sociedade contemporânea. Nem matemática nem Modelagem são "fins", mas sim "meios" para questionar a realidade vivida. Isso não significa que os alunos possam desenvolver complexas análises sobre a matemática no mundo social, mas que Modelagem possui o potencial de gerar algum nível de crítica. (Barbosa, 2001, p. 4)

Desse modo, conforme exposto pelo autor, tanto a MM quanto a matemática são consideradas como meios de compreender as situações reais vivenciadas para, então, questioná-las e, a partir disso, propor possíveis soluções para os problemas identificados. Vale dizer que os conteúdos e os conceitos matemáticos são trabalhados nas atividades de MM não como um fim em si mesmo. Considerando-se que o intuito é o de promover compreensão dos problemas reais e investigar possíveis soluções, a matemática é trabalhada conforme as necessidades que surgem ao longo do processo.

A partir dos aspectos discutidos pelos autores mencionados, entende-se que a MM, quando trabalhada na perspectiva da EMC, propõe uma concepção para os processos de ensino e aprendizagem da matemática pautada na problematização, na investigação e na reflexão, colocando os estudantes como agentes ativos na construção e no desenvolvimento de seus conhecimentos matemáticos e de sua criticidade.

\section{SELEÇÃO E ORGANIZAÇÃO DOS MATERIAIS PARA ANÁLISE}

A coleta dos dados para o desenvolvimento da pesquisa foi realizada por meio dos trabalhos produzidos por professores participantes do PDE. A investigação foi feita no site da Secretaria da Educação do estado do Paraná, no qual estão disponibilizadas as produções do PDE desde a implantação do programa, em 2007.

Para filtrar os trabalhos conforme os objetivos estabelecidos para a pesquisa, foi feita uma busca considerando-se a instituição de ensino Unespar campus de Campo Mourão e a palavra-chave Modelagem Matemática, resultando em trinta trabalhos.

Em seguida, foram lidos os resumos dos trabalhos, para identificar em quais perspectivas a MM foi utilizada. Dos 30 , foram selecionados 22 , dos quais oito fazem referência à $\mathrm{MM}$ na perspectiva da $\mathrm{EMC}$ e $14 \mathrm{a}$ abordam em perspectivas distintas, mas com propósitos convergentes com diversos aspectos da EMC, sendo, por isso, considerados para as análises. A perspectiva sociocrítica foi abordada em oito desses quatorze e os outros quatro consideram a $\mathrm{MM}$ em perspectivas variadas, como se pode verificar no Quadro 1.

Os trabalhos desenvolvidos por cada professor se desdobram em duas publicações distintas. Uma delas trata da produção didático-pedagógica $(\mathrm{P})$, que contempla o planejamento das atividades realizadas com os estudantes, e a outra, do artigo científico $(\AA)$, que detalha o desenvolvimento dessas atividades e as análises realizadas pelos professores. Para identificar cada um desses trabalhos, foram criados códigos alfanuméricos conforme os exemplos a seguir: A1 (artigo científico 1) e P10 (produção didático-pedagógica 10). 


\section{Quadro 1 - Relação dos trabalhos analisados e perspectiva em que a Modelagem Matemática (MM) foi trabalhada.}

\begin{tabular}{|c|c|c|c|c|}
\hline Código & Títulos & $\begin{array}{c}\text { Perspectiva } \\
\text { MM }\end{array}$ & Turma & Autoria \\
\hline $\begin{array}{l}\text { A1 } \\
\text { P1 }\end{array}$ & $\begin{array}{c}\text { Modelagem Matemática } \\
\text { na perspectiva da Educação } \\
\text { Matemática Crítica: melhorias na } \\
\text { quadra de esportes }\end{array}$ & EMC & $\begin{array}{l}9^{\circ} \text { ano do } \\
\text { ensino } \\
\text { fundamental }\end{array}$ & $\begin{array}{l}\text { (Toná e Silva e } \\
\text { Ceolim, 2016; } \\
\text { Toná e Ceolim, } \\
\text { 2016) }\end{array}$ \\
\hline $\begin{array}{l}\mathrm{A} 2 \\
\mathrm{P} 2\end{array}$ & $\begin{array}{c}\text { Modelagem Matemática e } \\
\text { merenda escolar: uma alternativa } \\
\text { pedagógica para o ensino da } \\
\text { matemática }\end{array}$ & EMC & $\begin{array}{l}7^{\circ} \text { ano do } \\
\text { ensino } \\
\text { fundamental }\end{array}$ & $\begin{array}{c}\text { (Pinheiro e } \\
\text { Ceolim, 2016a, } \\
\text { 2016b) }\end{array}$ \\
\hline $\begin{array}{l}\text { A3 } \\
\text { P3 }\end{array}$ & $\begin{array}{l}\text { Modelagem Matemática na } \\
\text { implantação de uma cisterna }\end{array}$ & EMC & $\begin{array}{l}2^{\circ} \text { ano do } \\
\text { ensino médio }\end{array}$ & $\begin{array}{c}\text { (Antonioli e } \\
\text { Ceolim, 2016a, } \\
\text { 2016b) }\end{array}$ \\
\hline $\begin{array}{l}\text { A4 } \\
\text { P4 }\end{array}$ & \begin{tabular}{|c|} 
Modelagem Matemática na \\
captação da água da chuva em \\
um colégio estadual do estado do \\
Paraná
\end{tabular} & EMC & $\begin{array}{l}4^{\circ} \text { ano do } \\
\text { ensino médio } \\
\text { Formação } \\
\text { Docente }\end{array}$ & $\begin{array}{c}\text { (Basaglia e } \\
\text { Ceolim, 2014a, } \\
\text { 2014b) }\end{array}$ \\
\hline 0 & $\begin{array}{c}\text { Modelagem Matemática } \\
\text { no ensino de matemática: } \\
\text { uma estratégia para o ensino } \\
\text { envolvendo o consumo racional } \\
\text { de água }\end{array}$ & Sociocrítica & $\begin{array}{l}9^{\circ} \text { ano do } \\
\text { ensino } \\
\text { fundamental }\end{array}$ & $\begin{array}{c}\text { (Silva e } \\
\text { Hermann, } \\
\text { 2014a, 2014b) }\end{array}$ \\
\hline $\begin{array}{l}\text { A6 } \\
\text { P6 }\end{array}$ & $\begin{array}{l}\text { Modelagem Matemática: uma } \\
\text { pesquisa na perspectiva da } \\
\text { educação fiscal }\end{array}$ & $\begin{array}{l}\text { Perspectiva da } \\
\text { Educação Fiscal }\end{array}$ & $\begin{array}{l}\text { 9o ano do } \\
\text { ensino } \\
\text { fundamental }\end{array}$ & $\begin{array}{c}\text { (Selis e } \\
\text { Hermann, } \\
\text { 2014a, 2014b) }\end{array}$ \\
\hline $\begin{array}{l}\text { A7 } \\
\text { P7 }\end{array}$ & $\begin{array}{c}\text { O consumo sustentável de } \\
\text { energia elétrica e o ensino de } \\
\text { funções por meio da Modelagem } \\
\text { Matemática }\end{array}$ & Sociocrítica & $\begin{array}{l}1^{\mathrm{o}} \text { ano do } \\
\text { ensino médio }\end{array}$ & $\begin{array}{l}\text { (Goes e Borges, } \\
\text { 2013a, 2013b) }\end{array}$ \\
\hline $\begin{array}{l}\text { A8 } \\
\text { P8 }\end{array}$ & $\begin{array}{l}\text { Pilhas e baterias, uso e descarte: } \\
\text { uma abordagem voltada para o } \\
\text { ensino da matemática }\end{array}$ & $\mathrm{MM}$ & $\begin{array}{l}\text { 7o ano do } \\
\text { ensino } \\
\text { fundamental }\end{array}$ & $\begin{array}{l}\text { (Martins e } \\
\text { Lorin, 2013a, } \\
\text { 2013b) }\end{array}$ \\
\hline $\begin{array}{l}\text { A9 } \\
\text { P9 }\end{array}$ & \begin{tabular}{|c|} 
Lixo, reciclagem e Modelagem \\
Matemática: uma investigação na \\
escola com os alunos do Ensino \\
Fundamental
\end{tabular} & Sociocrítica & $\begin{array}{l}9^{\circ} \text { ano do } \\
\text { ensino } \\
\text { fundamental }\end{array}$ & $\begin{array}{c}\text { (Parisotto e } \\
\text { Hermann, } \\
\text { 2012a, 2012b) }\end{array}$ \\
\hline $\begin{array}{l}\text { A10 } \\
\text { P10 }\end{array}$ & $\begin{array}{l}\text { Consumo abusivo de bebidas } \\
\text { alcoólicas por adolescentes: } \\
\text { uma proposta para a Educação } \\
\text { Estatística por meio da } \\
\text { Modelagem Matemática }\end{array}$ & $\mathrm{MM}$ & $\begin{array}{l}3^{\circ} \text { ano do } \\
\text { ensino médio }\end{array}$ & $\begin{array}{l}\text { (Zorzanelo e } \\
\text { Hermann, 2012; } \\
\text { Zorzanelo, } \\
\text { 2012) }\end{array}$ \\
\hline $\begin{array}{l}\text { A11 } \\
\text { P11 }\end{array}$ & $\begin{array}{c}\text { A Modelagem Matemática na } \\
\text { sala de aula: uma estratégia em } \\
\text { busca do uso racional de energia } \\
\text { elétrica }\end{array}$ & Sociocrítica & $\begin{array}{l}9^{\circ} \text { ano do } \\
\text { ensino } \\
\text { fundamental }\end{array}$ & $\begin{array}{c}\text { (Silva e } \\
\text { Hermann, } \\
\text { 2010a, 2010b) }\end{array}$ \\
\hline
\end{tabular}

EMC: Educação Matemática Crítica. 
Com base nos exemplos, deve-se considerar que os códigos com a primeira parte ordenada A1 e P1 se referem a duas produções de um mesmo professor, em que contemplam as atividades de uma única turma. $\mathrm{O}$ mesmo vale para os códigos com a primeira parte ordenada A2 e $\mathrm{P} 2, \mathrm{~A} 3$ e $\mathrm{P} 3$, e assim sucessivamente.

A seguir serão apresentados os procedimentos considerados para a interpretação e análise dos dados coletados para a pesquisa.

\section{PROCEDIMENTOS METODOLÓGICOS}

Todo o material selecionado foi fichado com destaque do que se considerou pertinente para o cumprimento dos objetivos estabelecidos para o desenvolvimento da pesquisa. As Ps e os As selecionados foram fichados sob olhar fundamentado pela EMC, tendo como critério salientar nos textos aspectos identificados quanto aos reflexos no planejamento das atividades de MM nas perspectivas adotadas, considerando-se, segundo as intenções de trabalho e as preocupações expressas pelos professores, como se deu a elaboração das tarefas; quais recursos de ensino foram utilizados; qual a abordagem da matemática durante o processo; quais discussões, análises e reflexões foram oportunizadas aos estudantes; e como essas atividades contribuíram para o seu desenvolvimento do pensamento crítico e reflexivo.

A interpretação e análise dos dados foi embasada na metodologia da análise textual discursiva proposta por Moraes (2003). Portanto, seguindo os procedimentos sugeridos pelo autor, de início os textos foram desmontados e, a priori, os materiais foram examinados detalhadamente. Fragmentaram-se esses textos retirando deles os trechos destacados, conforme o critério dos aspectos mencionados, que interessavam para as análises da pesquisa. Esses fragmentos foram agrupados conforme suas ideias convergentes e, enquanto agrupados, possibilitaram a construção de onze unidades de significado (US), sendo cada uma delas intitulada de acordo com o conceito geral identificado nos excertos.

$\mathrm{Na}$ segunda etapa foi realizada a análise do corpus, o qual consiste no conjunto de produções textuais - materiais selecionados e delimitados rigorosamente. Esses exprimem "discursos sobre fenômenos e que podem ser lidos, descritos e interpretados, correspondendo a uma multiplicidade de sentidos que a partir deles podem ser construídos" (Moraes, 2003, p. 194). Nessa etapa, a impregnação das informações contidas no corpus impulsionou a produção de diferentes significados pela ótica da EMC.

Foram estabelecidas, por meio dos métodos indutivo e intuitivo, relaçôes entre as unidades definidas anteriormente "combinando-as e classificando-as no sentido de compreender como esses elementos unitários podem ser reunidos na formação de conjuntos mais complexos" (Moraes, 2003, p. 197).

Nesse processo de construir as categorias com base nas informações contidas no corpus, emergiram duas categorias: planejamento, implementação e avaliação das atividades de Modelagem Matemática; e preocupação com a formação do senso crítico. 
$\mathrm{Na}$ terceira etapa foram elaborados os metatextos ${ }^{4}$ explicativos, que consistem no processo de comunicação da compreensão tida do todo. $\mathrm{Na}$ construção desses metatextos foram explicitados textos que subsidiaram as compreensões de cada categoria.

As US constituídas, que foram identificadas pelos códigos alfanuméricos de U1 a U11 (unidades de significado de um a onze), foram apresentadas com os metatextos das categorias, atreladas às explicações, concomitante à discussão das análises.

\section{DISCUSSÃO DAS ANÁLISES E RESULTADOS}

Nesta pesquisa foram analisados os aspectos referentes à elaboração e ao desenvolvimento das atividades implementadas. A análise subsidiou a constituição da primeira categoria, intitulada planejamento, implementação e avaliação das atividades de Modelagem Matemática, a qual emergiu a partir das sete unidades de significado:

- Integrar conteúdos matemáticos com situações da realidade (U1);

- A matemática permeando todo o processo (U2);

- Utilização prática dos conceitos e dos conteúdos matemáticos (U3);

- O uso de diferentes recursos didáticos (U4);

- Incentivo à pesquisa, à investigação, à leitura, à escrita e a experimentação (U5);

- O papel do professor mediante as atividades (U6);

- Avaliação de forma contínua (U7).

Dentre os temas abordados nos trabalhos investigados que possibilitaram a problematização, alguns deles envolveram questões específicas do cotidiano escolar, como a reforma da quadra escolar, a análise da viabilidade e a implantação do sistema de cisterna para a captação da água da chuva na escola e a análise da quantidade de energia e de proteína presentes no cardápio escolar.

Outros temas envolveram diretamente o contexto da casa dos estudantes, como o consumo sustentável da energia elétrica a partir da análise do consumo de energia dos eletrodomésticos, em que eles realizaram investigações em seus lares, e alguns tópicos relacionaram questões mais abrangentes que permeiam não apenas o cotidiano dos estudantes, mas o de toda a sociedade, como, por exemplo, o desperdício de água no município, o uso e o descarte de pilhas e baterias e a educação fiscal, que abordou especificamente os tributos fiscais e a aplicação dos recursos arrecadados.

A escolha dos temas corrobora a ideia de Skovsmose (2001), que salienta que o problema a ser estudado deve ser considerado pertinente e interessante na perspectiva dos estudantes e, além disso, as "referências à vida real parecem ser necessárias para estabelecer uma reflexão detalhada sobre a maneira como a matemática

4 Moraes (2003) enfatiza que, nessa análise textual qualitativa, "produz-se um metatexto, descrevendo e interpretando sentidos e significados que o analista constrói ou elabora a partir do referido corpus" (Moraes, 2003, p. 202). 
pode estar operando enquanto parte de nossa sociedade" (Skovsmose, 2000, p. 84). Sendo assim, nota-se que houve preocupação, por parte dos professores, em escolher um tema de estudos que fosse considerado importante pelos discentes, de modo a despertar neles maior interesse e envolvimento nas atividades e que tivesse potencial para reflexões sobre como a matemática compõe e influencia a vida das pessoas.

Isso demandou pesquisa, leitura e investigação por parte dos professores, pois não foram consideradas atividades prontas de livros didáticos ou de outro material previamente definido "por uma autoridade externa à sala de aula" (Skovsmose, 2000, p. 66), porque houve a justificativa da relevância das atividades, já que as intenções com esses trabalhos envolviam especificamente investigações quanto aos temas reais que cada professor propôs a ser estudado. $\mathrm{E}$ indo ao encontro sobre o que nos enfatiza Freire (2011) acerca da relação entre ensino e pesquisa - se dá de forma intrínseca, "não há ensino sem pesquisa e pesquisa sem ensino"(Freire, 2011, p. 14).

Dessa forma, antes de se iniciar a implementação das atividades aos estudantes, cada professor apresentou a proposta de trabalho para a classe e, no caso daqueles temas que envolviam diretamente situações da realidade escolar, a proposta também foi apresentada aos demais agentes da comunidade escolar, a fim de mostrar para os estudantes a importância de serem investigados problemas inerentes àquela situação real, alvo do estudo.

De acordo com Skovsmose (2008, p. 21), o ambiente de aprendizagem só se torna "um cenário para investigação se os alunos aceitam o convite"e, considerando-se ainda o que salienta Skovsmose (2001, p. 19), quando diz que "o problema deve ser concebido como relevante na perspectiva dos estudantes", verificou-se que, de modo geral, os estudantes acolheram os temas sugeridos pelos professores; em outras palavras, eles aceitaram o convite, ou pelo menos a maioria deles o aceitou.

Para realizar o planejamento das atividades, cada professor desenvolveu sua $\mathrm{P}$, conforme postas no Quadro 1, contemplando uma sequência de atividades diferenciadas entre si, as quais oportunizaram ações diversificadas aos estudantes, como "busca, seleção, organização e manipulação de informações" (Barbosa, 2004, p. 75), que se fazem presentes no processo de investigação.

A elaboração das atividades envolveu investigações como pesquisas de campo para a coleta dos dados necessários à problematização, incluindo observações, experimentos com medições e confecção de materiais de apoio ao trabalho; elaboração do roteiro de perguntas para realização de entrevistas; realização de pesquisas em diferentes referências para se conhecer de forma mais aprofundada $o$ tema de estudos; levantamento de hipóteses para a simplificação do/s problema/s; leitura e discussão de textos com os colegas em sala de aula; bem como produção de textos e realização de trabalho cooperativo/colaborativo com os estudantes em equipes e entre as equipes.

Verificou-se que o desenvolvimento das atividades realizadas pelos estudantes foi pensado pelo professor para que possibilitasse a exploração e/ou inserção de conteúdos e de conceitos matemáticos integrados a situações reais, assim como para mostrar exemplos da utilidade prática de alguns desses conteúdos. Contudo, mesmo que esses não tenham sido os objetivos principais na implementação das atividades, foram recursos estratégicos utilizados pelos professores para despertar a atenção e 
o interesse dos estudantes e conseguir, dessa maneira, caminhar rumo aos objetivos específicos, como promover análises, críticas e reflexões. Podemos verificar essas intenções dos professores quanto a esse planejamento nos próximos fragmentos:

- P8: "Elaboramos atividades que buscam uma conexão entre a matemática escolar e a matemática fora do contexto escolar, tendo como foco o descarte inadequado e muitas vezes inconsciente de pilhas e baterias" (p. 6; U1);

- P6: "Buscamos fazer uma conexão entre os conteúdos da disciplina de Matemática com a Educação Fiscal, com o objetivo de promover a formação social dos alunos" (p. 5; U1);

- A10: "Percebemos a importância de abordar temas contemporâneos nas aulas de Matemática, pois para muitos alunos a matemática é vista como uma disciplina distante da realidade, sem ligação com o cotidiano" (p. 3; $\mathrm{U} 1)$;

- A5: "O ensino de Matemática só faz sentido se permitir aos alunos a aplicação prática daquilo que lhes é ensinado” (p. 27; U3).

Como mencionado, além da preocupação em integrar os conteúdos e os conceitos matemáticos a situações reais, objetivou-se, em especial, que as situações exploradas propiciassem aos estudantes o pensamento de forma analítica, crítica e reflexiva referente às questões do cotidiano deles e/ou da sociedade de modo geral, o que vai ao encontro do enfatizado por Skovsmose (2001), quando aponta que não é suficiente que o estudante domine somente técnicas, algoritmos e modelos matemáticos, ele também deve se tornar capaz de fazer análises qualitativas e reflexões para que conheça o problema real em seus pormenores, de modo a propor soluções.

Tais atividades, orientadas pelos professores, permitiram que os estudantes desenvolvessem autonomia e aprendessem a pesquisar sobre algo que lhes era desconhecido, problematizando, investigando e fazendo reflexões relativas a situações-problema advindas de contextos nos quais eles próprios estão inseridos. Essas atividades, que envolveram problematizar e investigar, "não são separadas, mas articuladas no processo de envolvimento dos estudantes para abordar a atividade proposta" (Barbosa, 2004, p. 75), conforme identificado na análise realizada. Nos fragmentos a seguir, podem-se verificar algumas dessas ações:

- A7: "Para que houvesse uma constatação do consumo de energia elétrica residencial, foi elaborada uma tabela na qual os alunos teriam que observar durante 10 dias o consumo de energia de sua residência" (p.13; $\mathrm{U} 5)$;

- A5: "Os alunos realizaram a visita no centro de abastecimento de água para conhecer a forma que a água é captada e como é feito o seu tratamento pela SANEPAR [...], fizeram a coleta de dados, tendo como base o questionário elaborado em sala de aula" (p. 8; U5);

- A3: "Cada grupo saiu no pátio do colégio para medir as dimensões de dois edifícios e a área de suas respectivas coberturas com a utilização de uma trena" (p. 13; U5); 
- A9: "Os alunos buscaram conhecimentos sobre o tema nas diferentes fontes de pesquisa, na mídia impressa, em palestras sobre cooperativas de lixo reciclável e sobre o meio ambiente e, em especial, na mídia eletrônica" (p. 7; U5).

Concomitantemente a essas atividades diversificadas proporcionadas aos estudantes, também foram usados diferentes recursos didáticos durante as aulas: meios distintos de informação, como vídeos, filmes, textos impressos, mídias digitais do laboratório de informática da escola — softwares e internet e ferramentas matemáticas operacionais, como instrumentos de medição de massa, de comprimento e de volume, calculadora, compasso, transferidor e um pluviômetro que foi construído pelos estudantes em um dos trabalhos, dentre outros.

Mas, afinal, que relação tais recursos têm com a perspectiva norteadora desta pesquisa? Essa relação pode ser vista entre os diferentes meios de informação, os quais serviram de complemento da pesquisa investigativa, que contribuíram para que os estudantes conhecessem o tema em maior riqueza de detalhes e possibilitaram o confronto entre as diversas informações encontradas, sendo isso um pressuposto para reflexões críticas realizadas pelos estudantes ao utilizarem os diversos recursos didáticos. Aquelas ferramentas matemáticas operacionais foram importantes na construção do conhecimento matemático e no estabelecimento da relação entre a matemática e a realidade estudada. Vejamos alguns fragmentos que explicitam o uso desses recursos:

- P11: "Recursos didáticos: TV, pen drive, Laboratório de Informática, slides, vídeos do YouTube e textos" (p. 3; U4);

- A5: "Eles fizeram a planificação e construção de um cubo, para compreender o conceito envolvido na medida de volume de água [...], construíram gráficos no caderno e também no computador, analisando os gastos de água durante um ano nas suas residências" (p. 8; U4);

- A1: "Utilizou-se alguns instrumentos de medida, como fita métrica, trena e metro de carpinteiro" (p. 11; U4);

- A8: "Foi traçada a circunferência com o compasso e, com o auxílio de régua e transferidor, desenharam o ângulo com vértices no centro do círculo dividindo-os na medida desejada" (p. 20; U4);

- P3: "Os alunos construirão as maquetes juntamente com a maquete da cisterna instalada no edifício para melhor visualização do projeto final" (p. 25; U4).

Diante do encaminhamento dessas atividades para os estudantes e da utilização de recursos didáticos distintos, a forma de avaliação adotada pelos professores também teve estrutura diferenciada em relação ao formato de avaliação das aulas consideradas tradicionais ${ }^{5}$. $\mathrm{Na}$ maioria dos trabalhos verificou-se que a avaliação

5 "Aquela em que o aluno fica a maior parte do tempo envolvido com resolução de exercícios" (Skovsmose, 2000, p. 1). 
foi feita continuamente, considerando-se os resultados alcançados pelos estudantes em cada etapa das atividades.

Em todas as etapas houve o acompanhamento, a mediação e o auxílio do professor, evidenciando o que Skovsmose (2000, p. 13) observa ao afirmar que "o professor tem o papel de orientar", e assim o fizeram, sem apresentar respostas ou soluções prontas para os estudantes, mas sempre questionando-os, recebendo, em contrapartida, suas indagações, buscando fazê-los refletir quanto à existência de coerência entre o que estavam executando em relação ao contexto - interpretação - e quanto aos caminhos escolhidos e aos cálculos realizados, estimulando, além da pergunta, "a reflexão crítica sobre a própria pergunta" (Freire, 2011, p. 34).

Quanto à abordagem dos conteúdos matemáticos, verificou-se que estiveram presentes durante toda a resolução das atividades, em alguns momentos mais do que em outros. Coube aos professores retomar alguns conteúdos e/ou conceitos matemáticos já estudados, bem como a formalização dos cálculos realizados em termos dos conteúdos e dos conceitos matemáticos envolvidos. O papel desempenhado pelos docentes pode ser verificado nos seguintes fragmentos:

- A7: "Conforme foi evoluindo para questionamentos, o grupo conseguiu estabelecer uma relação satisfatória entre filme, poema e a Matemática” (p. 12; U6);

- A5: "A professora continuou questionando, e eles ainda estavam com dúvidas" (p. 11; U6);

- A8: "Para transferir os dados para o gráfico de setores foi preciso retomar os conceitos de ângulo e de porcentagem, relacionando-os como recursos na construção desse tipo de gráfico" (p. 20; U2).

Portanto, nessa forma de intervenção dos docentes, ficando eles atentos para interceder, quando necessário, simultaneamente, os estudantes foram avaliados nas atividades em aspectos como suas atuações diante das discussões feitas em sala; argumentos e hipóteses levantados; sugestões dadas; textos dissertativos produzidos acerca do que conheciam sobre o tema antes e/ou após pesquisas e discussões feitas; elaboração de perguntas para as entrevistas; forma como abordaram os entrevistados; trabalho colaborativo em equipe; entre outras atividades de aspectos qualitativos realizadas.

Além disso, foram avaliados os resultados obtidos pelos estudantes na coleta de dados feita a partir das medições, dos levantamentos de preços, das observações e das experimentações, e, ainda, na confecção dos materiais de auxílio, nos casos em que houve a necessidade de confeccioná-los, e também todos os cálculos realizados por eles.

Nos fragmentos apresentados a seguir são evidenciadas as propostas de avaliação consideradas em algumas das atividades:

- P11: "A avaliação [...] será realizada por meio de relatórios escritos pelos alunos, pesquisas, leitura de textos, participação nos debates, realização e descrição detalhada dos cálculos [...], produção escrita dos alunos" (p. 4; U7); 
- P5: "Os alunos serão avaliados de forma diagnóstica e continua, com predomínio dos aspectos qualitativos sobre os quantitativos" (p. 7; U7);

- P2: "Serão seguidos alguns processos avaliativos como: avaliação diagnóstica, somativa, processual, qualitativa e formativa” (p. 10; U7);

- P9: "Serão utilizados diferentes instrumentos de avaliação, tais como: trabalhos em grupo, pesquisas, participação nas discussões e relatórios escritos pelos alunos" (p. 7; U7);

- P4: "Avaliação da aprendizagem dos alunos se dará de forma processual, contínua, formativa e diagnóstica [...], deverá diagnosticar as dificuldades do aluno" (p. 10; U7).

Verificou-se que nas propostas de avaliação dos professores não foi considerado apenas o resultado final ou a solução encontrada pelos estudantes. Desse modo, os resultados obtidos por eles não foram avaliados, objetivamente, como certo ou errado. Figueiredo e Kato (2012, p. 280) identificam que "não existem na literatura muitos estudos sobre a avaliação da aprendizagem dos alunos, durante tais atividades"; no caso das atividades de MM analisadas, verifica-se que houve preocupação dos professores em avaliar o conjunto de ações empreendidas pelos estudantes, ponderando a criatividade, a iniciativa, a forma de pensamento crítico e reflexivo, os discursos produzidos por eles, a mobilização de ideias, entre outras ações de aspectos qualitativos, isto é, o foco avaliativo não foi, exclusivamente, quanto à aprendizagem dos conteúdos e dos conceitos matemáticos. A avaliação deu-se de maneira abrangente, considerando-se todo o processo, todas as ações e as produções dos estudantes.

Analisando-se os critérios considerados nessa forma de avaliação, houve contraposição ao que Borba e Skovsmose (2001) identificam como ideologia da certeza, a qual atribui à matemática um caráter de sistema perfeito, estrutura fechada, linear e infalível, em que são resolvidos problemas em busca de solução única considerada ótima, suficiente e incontestável, denotando um poder absoluto, no sentido de verificar e interpretar se a matemática está sendo transformada em uma linguagem de poder.

Ressalta-se que em atividade de MM desenvolvida na perspectiva da EMC, por sua característica, são buscadas possíveis soluções para os problemas advindos das situações reais elencadas. Com isso, os estudantes podem apresentar diferentes formas de resoluções e chegar a distintas soluções para um mesmo problema, verificando que não necessariamente existe uma única solução para um problema que envolva situações reais.

A partir das análises realizadas, verificou-se que um aspecto comum a todos os trabalhos explorados é a preocupação dos professores em proporcionar atividades que contribuam para, além do desenvolvimento do conhecimento científico dos estudantes, a elaboração de trabalhos que permitam o desenvolvimento da autonomia, da criticidade e da capacidade desses jovens de propor soluções para os problemas da sociedade.

A segunda categoria, preocupação com a formação do senso crítico, revelou-se a partir do agrupamento das quatro unidades de significado: 
- Conhecimento aprofundado do problema (U8);

- Aula democrática com criticidade (U9);

- Formar para o exercício da cidadania (U10);

- Preocupação com questões socioambientais (U11).

Com base nas análises feitas, há de considerar que os estudantes puderam conhecer os problemas reais de forma consideravelmente detalhada, analisando o contexto da problemática com riqueza de aspectos. É nessa perspectiva que Meyer, Caldeira e Malheiros (2011, p. 28) enfatizam que "o aluno tem o direito de ver o problema na importância que ele tem para a sociedade", portanto, para que os estudantes compreendam a relevância que o problema abordado tem para as pessoas envolvidas no contexto, é preciso que haja discussões, análises e reflexões que contemplem o máximo possível de aspectos envolvidos na situação, sejam eles quantitativos ou qualitativos.

As pessoas tendem a ver situações de modos distintos, pois enxergam fatos por perspectivas diferentes, isso devido à subjetividade de cada indivíduo, que é reflexo do contexto no qual ele se insere, da sua realidade, das experiências vividas, das suas referências e dos sonhos que tem. Por isso, quando estudantes discutem acerca de um problema real, eles aprendem juntos, a partir de um diálogo democrático, a respeitar a opinião e a visão das outras pessoas.

Os fragmentos a seguir representam a ideia central dos textos que sugerem alguns desses momentos de discussões, análises e reflexões em sala e/ou o planejamento das atividades, feito pelos professores, quando a sala de aula foi "entendida como um espaço democrático, onde o diálogo, no sentido de ação dialógica, é a forma de comunicação entre os participantes"(Araújo, 2009, p. 59). Os fragmentos A6 e A5 representam algumas das falas de estudantes, conforme explicitado pelos professores nos textos:

- P2: "Seguindo a proposta, se abrirá uma discussão sugerida pela professora sobre questões que eles julguem, necessitam ser melhoradas no espaço escolar e, em grupos, farão apontamentos e reflexões, expressando opiniões sobre o assunto" (p. 8; U9);

- P5: "A ideia dessa proposta, não é apenas instrumentar matematicamente os alunos, mas prepará-los para a atuação crítica na sociedade" (p. 5; U10);

- A6: "Sem nota fiscal não tem ICMS e sem ICMS não tem escolas, hospitais, postos de saúde e nem pagamento de professores. $\mathrm{O}$ tributo é uma obrigação de pagar e deve ser pago" (p. 16; U8);

- A5: "Não é certo eu gastar menos água e ter que pagar o mesmo valor!" (p. 13; U8);

- A2: "Os grupos socializaram suas ideias, concluindo que o valor da verba diária repassada do Governo Federal para cada aluno é muito baixa, e que por isso, os Estados e Municípios devem complementá-la" (p. 13; U10).

Trocando ideias, expondo pensamentos, elencando variáveis diferentes que interferem no problema e propondo possíveis soluções por caminhos diferentes, 
nesse ambiente democrático de diálogo entre estudantes, com mediação e contribuição do professor, os estudantes conseguem conhecer melhor o problema e, assim, apontar possíveis soluções coerentes.

Aulas de matemática que proporcionam ambientes como esses contribuem para o desenvolvimento da criticidade e da autonomia dos estudantes, uma vez que as situações-problema são analisadas criticamente considerando grande parte dos seus pressupostos e, como nesse ambiente de aprendizagem proporcionado pela MM trabalhada na perspectiva da EMC os estudantes têm maior liberdade tanto para expressar opinião, ponto de vista, como para investigar e propor soluções para o problema, eles tendem a sentir-se mais confiantes e com maior autonomia para lidar com outras situações reais, o que pode orientá-los, segundo Araújo (2009, p. 59), a "levarem essas atitudes para suas vidas na sociedade".

Os fragmentos a seguir nos remetem à ideia central dos trechos agrupados, os quais expressam os conceitos discutidos nos parágrafos anteriores:

- A11: "Cada um relatou o que estava fazendo de errado e precisava melhorar e também fizeram críticas a seus familiares os quais também cometem tais erros" (p. 19; U9);

- A5: "Eles disseram que se a água fosse cobrada por cada metro cúbico usado seria melhor, tanto para economizar a água como também no valor a ser pago" (p. 14; U9);

- A4: "Após as discussões e reflexões os alunos constataram que a água [...] pode acabar e, por isso, exige cuidados em relação à quantidade de uso, à sua qualidade, às suas fontes, à sua distribuição desigual pelo planeta, além de planejamento e custeio de tratamento" (p. 12; U9);

- A8: "Percebeu-se que o objetivo da atividade [...] foi atingido, pois os mesmos se propuseram a dialogar com os familiares a respeito de melhor observar as indicações ao comprar pilhas" (p. 11; U10).

Trabalhar as atividades de MM com o intuito de contribuir para a formação dos estudantes para o exercício da cidadania foi uma preocupação comum a todos os professores. De acordo com as análises feitas pelos professores durante a realização das atividades, conforme relatado nos artigos por eles escritos, ficou explicitado que aulas democráticas proporcionam aos estudantes investigações, discussões, análises e reflexões. Essas ações contribuem para o desenvolvimento do senso crítico e da autonomia, bem como subsidiam a compreensão dos problemas reais, favorecendo a formação de indivíduos que terão capacidade de exercer sua cidadania de forma crítica.

Skovsmose (1992, p. 16) alerta que "um dos objetivos da educação tem de ser a preparação para uma cidadania crítica”, observando que uma democracia deve dar condições para que as pessoas possam atuar criticamente na sociedade. $\mathrm{O}$ autor faz esse alerta por considerar que a democracia também diz respeito à obtenção de "condições materiais e éticas e à possibilidade de participação e reação"(Skovsmose, 1992, p. 10) dos indivíduos, estes constituem a maioria da população, capacitados a analisar, questionar e reagir às decisões e às ações dos governantes, que são uma minoria representativa. 
Nesse raciocínio, corroboramos Araújo (2009, p. 63) ao compreender que "aqueles que não têm acesso à matemática estão sujeitos ao controle e à vontade dos detentores do poder" e que essa condição de aceitação e subordinação sem um questionamento crítico pode "reforçar as desigualdades sociais, o racismo, discriminações sócio econômicas" (Araújo, 2009, p. 63).

Os próximos fragmentos abordam as preocupações dos professores relativas à formação do pensamento crítico e a algumas conquistas para a sociedade a partir do trabalho desenvolvido, conforme explicita o quarto fragmento:

- A6: "Procuramos apresentar as bases da cidadania desenvolvendo a consciência dos alunos sobre a participação do produto social que é concedido aos cidadãos através do recolhimento dos impostos e investida em áreas como educação, saúde, segurança e outros benefícios" (p. 3; U10);

- P4: "Fomos motivados a investigar a importância e os benefícios ambientais, educacionais, econômicos e sociais que o aproveitamento da água da chuva proporciona pela implantação do sistema de cisterna que esta instituição possui" (p. 5; U10);

- P1: "Deve-se propiciar ao aluno um envolvimento que contribui para que o mesmo tenha uma visão mais ampla dos problemas matemáticos, possibilitando sua intervenção nos problemas reais do meio social onde convive [...], capaz de contribuir na sua formação crítica" (p. 4; U10);

- A8: "Em entrevista com o prefeito municipal a fim de verificar quais encaminhamentos poderiam ser dados aos dispositivos recolhidos, percebemos o sucesso do projeto [...]. O resultado foi a assinatura de um projeto de Lei [...] que dispõe sobre a coleta e o destino de pilhas e baterias no município" (p. 22; U10).

Mas o que é o exercício da cidadania? Como exercê-la? Entende-se que o exercício da cidadania está relacionado não apenas ao conhecimento e ao cumprimento dos direitos e dos deveres do cidadão perante a sociedade, mas também à contribuição deste para a transformação de uma sociedade justa, igualitária e humana, preocupada com a preservação dos recursos naturais do planeta e com a qualidade de vida de todos.

Logo, com base nas ideias discutidas por Skovsmose (1992), compreende-se que, para exercer sua cidadania, o indivíduo necessita de um conjunto de capacidades. Capacidade de pensar por si mesmo, de analisar e de refletir acerca de fatos e acontecimentos inerentes à sociedade, isso nos âmbitos sociopolítico, ambiental, econômico e cultural, capacidade de identificar possíveis causas de problemas referentes à sociedade, de mudar de atitude diante destes e de propor soluções a eles, sendo um agente ativo de transformação da sociedade a que pertence.

Ao compreender que o exercício da cidadania inclui a contribuição para a preservação dos recursos naturais do nosso planeta, observou-se que houve preocupação da maioria dos professores em abordar temas que envolvessem questões socioambientais. De acordo com Skovsmose (2001), isso satisfaz um dos critérios fundamentais para a seleção do problema, intitulado por ele como objetivo, em que 
"o problema deve ter uma relação próxima com problemas sociais objetivamente existentes"(Skovsmose, 2001, p. 20-21), que é o caso dos problemas socioambientais.

Esses professores contribuíram para que os estudantes conhecessem melhor alguns problemas reais relativos a questões ambientais. Essas atividades oportunizaram aos estudantes reflexões a respeito de seus papéis em ações cotidianas, as quais contribuem para o agravamento de problemas socioambientais.

Nos fragmentos apresentados a seguir é possível identificar a importância dada pelos professores ao trabalho com a MM a partir de temas que envolvem questões do âmbito socioambiental:

- P3: "Direcionar o aluno a investigar problemas ambientais da sua comunidade envolvendo a qualidade de vida e dando subsídios para que possa discutir e tomar decisões que envolvam tais problemas"(p. 9; U11);

- P7: "A discussão girará em torno do tema sustentabilidade, com enfoque no Programa Selo Procel" (p. 15; U11);

- P5: "A finalidade é educar os alunos para a sustentabilidade socioambiental" (p. 7; U11);

- A3: "Com a finalidade de conscientização pelo desenvolvimento sustentável no intuito de promover futuras ações e posturas responsáveis diante de problemas ambientais globais" (p. 8; U11).

As análises mostram que as atividades de MM realizadas em uma perspectiva crítica, seja da EMC propriamente dita ou de outras perspectivas que propõem trabalhos de investigações, de discussões, de análises e de reflexões para o desenvolvimento do senso crítico e da autonomia dos estudantes, têm potencial para desenvolver as capacidades discutidas anteriormente.

É importante salientar que não está sendo defendida uma forma linear e única de se trabalhar a matemática escolar, de maneira a contribuir para o desenvolvimento de tais capacidades, uma vez que existem na literatura outras propostas de trabalho que oferecem essas possibilidades, ou algumas delas.

\section{CONSIDERAÇÕES FINAIS}

As análises, como reflexos da abordagem das atividades de MM na perspectiva da EMC, evidenciaram, conforme discutido na primeira categoria, um trabalho com a matemática a partir de situações reais existentes na sociedade. De acordo com o planejado pelos professores, as atividades, na perspectiva estudada, possibilitaram mostrar aos estudantes a relevância da matemática na compreensão de problemas reais e na busca de soluções para eles, promovendo, consequentemente, a utilização prática dos conceitos e dos conteúdos matemáticos para cumprir os objetivos de possibilitar aos estudantes análises, críticas e reflexões relativas a esses problemas abordados.

Nessa forma de trabalho, utilizaram-se estrategicamente diferentes recursos didáticos, havendo incentivo à busca de conhecimento do tema por meio da pesquisa investigativa, composta por diversificadas ações realizadas pelos estudantes que contribuíram para o desenvolvimento da autonomia e da autoconfiança ao perceberem 
que podem adotar essa postura investigativa de maneira analítica, crítica e reflexiva para buscar soluções para outras situações-problema reais identificadas, sejam elas relativas a pequenos grupos sociais aos quais pertençam ou mais abrangentes referentes à sociedade como um todo, como foi o caso dos problemas socioambientais.

Como explanado na segunda categoria, a busca por conhecer de forma mais aprofundada os problemas reais proporcionou aos estudantes a oportunidade de aprender a refletir quanto aos aspectos e às circunstâncias que envolveram a situação-problema investigada, a respeitar a opinião alheia e as formas de pensamento divergentes, a compreender que um acontecimento pode ser percebido por perspectivas distintas, estabelecendo-se, nessa conjuntura, uma relação democrática permeada pelo diálogo entre estudantes e professor, além de propiciar maior envolvimento entre os estudantes e a comunidade escolar.

Dessa forma, por meio das atividades trabalhadas, verificou-se que houve contribuição para o desenvolvimento do senso crítico, do respeito ao modo de pensar do outro e da preparação para o exercício da cidadania. Além da oportunidade de promover: a conscientização para questões globais, como as do âmbito socioambiental, tanto nos estudantes como em seus amigos e parentes bem como nas comunidades locais por meio do relato dos estudantes sobre o trabalho realizado; o desenvolvimento da autonomia; e a capacitação e o encorajamento dos estudantes para propor soluções a problemas da sociedade. Esses resultados possivelmente promoveram transformações na forma de pensamento crítico e nas atitudes dos estudantes.

Como consequência, abordagens dessa natureza extrapolam a matemática formal, geralmente apresentada nos livros didáticos da EB que os professores, muitas vezes, seguem à risca, podem possibilitar aos estudantes a compreensão de que é possível desenvolver uma forma de pensamento crítico e reflexivo por meio da matemática que os capacite e os encoraje a realizar mudanças sociais.

Considerando-se o que é salientado por meio dos referenciais teóricos aqui utilizados, entende-se que qualquer que seja a contribuição, no sentido de promover uma educação que seja crítica e que capacite os estudantes para além daquilo que é técnico e científico, é importante para que eles se tornem pessoas capazes de promover transformações na sociedade a que pertencem. Essa forma de pensar acerca da maneira de se ensinar matemática corrobora o entendimento de Skovsmose (2001, p. 85), quando afirma que "o conhecimento tecnológico, em si, é incapaz de predizer e analisar os resultados de sua própria produção; reflexões são necessárias".

Para tanto, conforme explicitaram os professores, autores dos trabalhos analisados, o processo educacional como um todo deve ser constantemente debatido e repensado, gerando, consequentemente, necessidade de mudanças nos processos de ensino e aprendizagem da matemática.

Em vez de esperar iniciativas advindas de políticas educacionais ou de algum setor responsável, cada professor pode iniciar essa mudança dentro da sua sala de aula propondo atividades como as que foram trabalhadas pelos professores que participaram do PDE, pois "essa é uma forma de trabalhar questões políticas e democracia na micro-sociedade da sala de aula" (Araújo, 2009, p. 65), em que 
são dados os primeiros passos para a transformação das aulas de matemática e da formação dos estudantes.

Além disso, o professor pode promover discussões com outros professores, a fim de provocar debates acerca de como eles podem se organizar e pensar possíveis formas de abordagem para que as suas aulas possibilitem a formação de estudantes mais críticos. Lembrando sempre que "educação não transforma o mundo. Educação muda pessoas. Pessoas transformam o mundo" (Freire, 1987, p. 87) e atividades de $\mathrm{MM}$, na perspectiva da EMC, favorecem essas concepções.

\section{REFERÊNCIAS}

ANTONIOLI, R. M.; CEOLIM, A. J. Modelagem matemática na implantação de uma cisterna. In: PARANÁ. Secretaria de Estado da Educação. Superintendência de Educação. Os desafios da escola pública paranaense na perspectiva do professor PDE. Curitiba: SEED/PR, 2016a.v. 1.(Cadernos PDE).p. 2-19. Disponível em: http://www. diaadiaeducacao.pr.gov.br/portals/cadernospde/pdebusca/producoes_pde/2016/2016_ artigo_mat_unespar-campomourao_rosineiamartinsantoniolichichetti.pdf. Acesso em: mar. 2020.

ANTONIOLI, R. M.; CEOLIM, A. J. Modelagem matemática na implantação de uma cisterna. In: PARANÁ. Secretaria de Estado da Educação. Superintendência de Educação. Os desafios da escola pública paranaense na perspectiva do professor PDE. Curitiba: SEED/PR, 2016b. v. 2. (Cadernos PDE). p. 2-31. Disponível em: http://www.diaadiaeducacao.pr.gov.br/portals/cadernospde/pdebusca/producoes_ pde/2016/2016_pdp_mat_unespar-campomourao_rosineiamartinsantoniolichichetti. pdf. Acesso em: mar. 2020.

ARAÚJO,J.L.Uma abordagem sócio-crítica da modelagem matemática: a perspectiva da educação matemática crítica. Alexandria: Revista de Educação em Ciência e Tecnologia, v. 2, n. 2, p. 55-68, jul. 2009. Disponível em: https://periodicos.ufsc.br/ index.php/alexandria/article/view/37948/28976. Acesso em: dez. 2019.

BARBOSA, J. C. Modelagem na educação matemática: contribuições para o debate teórico. In: REUNIÃO ANUAL DA ANPED, 2001, Caxambu. Anais... Rio de Janeiro: ANPED, 2001. 1 CD-ROM.

BARBOSA, J. C. Modelagem matemática: o que é? por que? como? Revista Veritati, Salvador, n. 4, p. 73-80, 2004.

BASAGLIA, C. M.; CEOLIM, A. J. Modelagem matemática na captação da água da chuva em um colégio estadual do estado do Paraná. In: PARANÁ. Secretaria de Estado da Educação. Superintendência de Educação. Os desafios da escola pública paranaense na perspectiva do professor PDE. Curitiba: SEED/PR, 2014a. v. 1. (Cadernos PDE). p. 2-26. Disponível em: http://www.diaadiaeducacao.pr.gov.br/portals/cadernospde/ pdebusca/producoes_pde/2014/2014_unespar-campomourao_mat_artigo_cristina_ marta_basaglia.pdf. Acesso em: mar. 2020.

BASAGLIA, C. M.; CEOLIM, A. J. Modelagem matemática na captação da água da chuva em um colégio estadual do estado do Paraná. In: PARANÁ. Secretaria de Estado 
da Educação. Superintendência de Educação. Os desafios da escola pública paranaense na perspectiva do professor PDE. Curitiba: SEED/PR, 2014b. v. 2. (Cadernos PDE). Disponível em: http://www.diaadiaeducacao.pr.gov.br/portals/cadernospde/pdebusca/ producoes_pde/2014/2014_unespar-campomourao_mat_pdp_cristina_marta_basaglia. pdf. Acesso em: mar. 2020.

BORBA, M. C.; SKOVSMOSE, O. A ideologia da certeza em educação matemática. In: SKOVSMOSE, O. (org.). Educação matemática crítica: a questão da democracia. São Paulo: Papirus, 2001.p. 127-148.

CEOLIM, A. J.; CALDEIRA, A. D. Educação matemática crítica: aproximações da teoria de Skovsmose com concepções de modelagem de alguns pesquisadores brasileiros. In: CONFERÊNCIA NACIONAL SOBRE MODELAGEM NA EDUCAÇÃO MATEMÁTICA, 8., 2013, Santa Maria. Anais... Santa Maria: Centro Universitário Franciscano, 2013. 1 CD-ROM.

FIGUEIREDO, D. F.; KATO, L. A. Uma proposta de avaliação de aprendizagem em atividades de modelagem matemática na sala de aula. Acta Scientiae, Canoas, v. 14, n. 2, p. 276-294, maio/ago. 2012.

FREIRE, P. Pedagogia do oprimido. 17. ed. Rio de Janeiro: Paz e Terra, 1987.

FREIRE, P. Pedagogia da autonomia: saberes necessários à prática educativa. São Paulo: Paz e Terra, 2011.

GOES, R.A.; BORGES, F. A. O consumo sustentável de energia elétrica e o ensino de funções por meio da Modelagem Matemática. In: PARANÁ. Secretaria de Estado da Educação. Superintendência de Educação. Os desafios da escola pública paranaense na perspectiva do professor PDE. Curitiba: SEED/PR, 2013a.v. 1. (Cadernos PDE). p. 2-19. Disponível em: http://www.diaadiaeducacao.pr.gov.br/portals/cadernospde/ pdebusca/producoes_pde/2013/2013_fecilcam_mat_artigo_roberto_aparecido_de_ goes.pdf. Acesso em: mar. 2020.

GOES, R. A.; BORGES, F. A. O consumo sustentável de energia elétrica no ensino de funções por meio da modelagem matemática. In: PARANÁ. Secretaria de Estado da Educação. Superintendência de Educação. Os desafios da escola pública paranaense na perspectiva do professor PDE. Curitiba: SEED/PR, 2013b. v. 2. (Cadernos PDE). p. 2-60. Disponível em: http://www.diaadiaeducacao.pr.gov.br/portals/cadernospde/ pdebusca/producoes_pde/2013/2013_fecilcam_mat_pdp_roberto_aparecido_de_goes. pdf. Acesso em: mar. 2020.

MARTINS, D. A. B.; LORIN, J. H. Pilhas e baterias, uso e descarte: uma abordagem voltada para o ensino da matemática. In: PARANÁ. Secretaria de Estado da Educação. Superintendência de Educação. Os desafios da escola pública paranaense na perspectiva do professor PDE. Curitiba: SEED/PR, 2013a. v. 1. (Cadernos PDE). Disponível em: http://www.diaadiaeducacao.pr.gov.br/portals/cadernospde/pdebusca/ producoes_pde/2013/2013_fecilcam_mat_artigo_dalva_aparecida_borges_martins.pdf. Acesso em: mar. 2020.

MARTINS, D. A. B.; LORIN, J. H. Usando modelagem matemática para discutir o uso e o descarte de pilhas e baterias. In: PARANÁ. Secretaria de Estado da Educação. Superintendência de Educação. Os desafios da escola pública paranaense na 
perspectiva do professor PDE. Curitiba: SEED/PR, 2013b. v. 2. (Cadernos PDE). p. 2-55. Disponível em: http://www.diaadiaeducacao.pr.gov.br/portals/cadernospde/ pdebusca/producoes_pde/2013/2013_fecilcam_mat_pdp_dalva_aparecida_borges_ martins.pdf. Acesso em: mar. 2020.

MEYER, J. F. C. A.; CALDEIRA, A. D.; MALHEIROS, A. P. S. Modelagem em educação matemática. Belo Horizonte: Autêntica, 2011.

MORAES, R. Uma tempestade de luz: a compreensão possibilitada pela análise textual discursiva. Ciência \& Educação, Bauru, v. 9, n. 2, p. 191-211, dez. 2003. https://doi. org/10.1590/S1516-73132003000200004

PARISOTTO, M.J. R.; HERMANN, W. Lixo, reciclagem e modelagem matemática: uma investigação na escola com os alunos do ensino fundamental. In: PARANÁ. Secretaria de Estado da Educação. Superintendência de Educação. O professor PDE e os desafios da escola pública paranaense. Curitiba: SEED/PR, 2012a. v. 1. (Cadernos PDE). p. 2-18. Disponível em: http://www.diaadiaeducacao.pr.gov.br/ portals/cadernospde/pdebusca/producoes_pde/2012/2012_fecilcam_mat_artigo_ maria_joanina_rodrigues.pdf. Acesso em: mar. 2020.

PARISOTTO, M.J. R.; HERMANN, W. Lixo, reciclagem e modelagem matemática: uma investigação na escola com os alunos do ensino fundamental. In: PARANÁ. Secretaria de Estado da Educação. Superintendência de Educação. O professor PDE e os desafios da escola pública paranaense: produção didático-pedagógica. Curitiba: SEED/PR, 2012b. v. 2. (Cadernos PDE). p. 2-16. Disponível em: http://www. diaadiaeducacao.pr.gov.br/portals/cadernospde/pdebusca/producoes_pde/2012/2012_ fecilcam_mat_pdp_maria_joanina_rodrigues.pdf. Acesso em: mar. 2020.

PINHEIRO, S. M. F.; CEOLIM, A. J. Modelagem matemática e merenda escolar: uma alternativa pedagógica para o ensino da matemática. In: PARANÁ. Secretaria de Estado da Educação. Superintendência de Educação. Os desafios da escola pública paranaense na perspectiva do professor PDE. Curitiba: SEED/PR, 2016a. v. 1. (Cadernos PDE). p. 2-19. Disponível em: http://www.diaadiaeducacao.pr.gov. br/portals/cadernospde/pdebusca/producoes_pde/2016/2016_artigo_mat_unesparcampomourao_soniamariafeitosa.pdf. Acesso em: mar. 2020.

PINHEIRO, S. M. F.; CEOLIM, A. J. Modelagem matemática e merenda escolar: uma alternativa pedagógica para o ensino da matemática. In: PARANÁ. Secretaria de Estado da Educação. Superintendência de Educação. Os desafios da escola pública paranaense na perspectiva do professor PDE. Curitiba: SEED/PR, 2016b. v. 2. (Cadernos PDE). p. 2-27. Disponível em: http://www.diaadiaeducacao.pr.gov. br/portals/cadernospde/pdebusca/producoes_pde/2016/2016_pdp_mat_unesparcampomourao_soniamariafeitosa.pdf. Acesso em: mar. 2020.

SELIS, J.; HERMANN, W. Modelagem matemática: uma proposta de ensino de matemática na perspectiva da educação fiscal. Curitiba: SEED/PR, 2014a. Disponível em: http://www.diaadiaeducacao.pr.gov.br/portals/cadernospde/pdebusca/producoes_ pde/2014/2014_unespar-campomourao_mat_pdp_jovelino_selis.pdf. Acesso em: mar. 2020. 
SELIS, J.; HERMANN, W. Modelagem matemática: uma pesquisa na perspectiva da educação fiscal. In: PARANÁ. Secretaria de Estado da Educação. Superintendência de Educação. Os desafios da escola pública paranaense na perspectiva do professor PDE. Curitiba: SEED/PR, 2014b.v. 1. (Cadernos PDE).p. 2-18. Disponível em: http://www. diaadiaeducacao.pr.gov.br/portals/cadernospde/pdebusca/producoes_pde/2014/2014_ unespar-campomourao_mat_artigo_jovelino_selis.pdf. Acesso em: mar. 2020.

SILVA, S. A. F.; HERMANN, W. A modelagem matemática na sala de aula: uma estratégia em busca do uso racional de energia elétrica. In: PARANÁ. Secretaria de Estado da Educação. Superintendência de Educação. O professor PDE e os desafios da escola pública paranaense. Curitiba: SEED/PR, 2010a.v.1. (Cadernos PDE).p. 3-29. Disponível em: http://www.diaadiaeducacao.pr.gov.br/portals/cadernospde/pdebusca/ producoes_pde/2010/2010_fecilcam_mat_artigo_sueli_aparecida_francischini_da_ silva.pdf. Acesso em: mar. 2020.

SILVA, S. A. F.; HERMANN, W. A modelagem matemática na sala de aula: uma estratégia em busca do uso racional de energia elétrica. In: PARANÁ. Secretaria de Estado da Educação. Superintendência de Educação. O professor PDE e os desafios da escola pública paranaense: produção didático-pedagógica. Curitiba: SEED/PR, 2010b. v. 2. (Cadernos PDE). p. 2-26. Disponível em: http://www.diaadiaeducacao. pr.gov.br/portals/cadernospde/pdebusca/producoes_pde/2010/2010_fecilcam_mat_ pdp_sueli_aparecida_francischini_da_silva.pdf. Acesso em: mar. 2020.

SILVA, M. C.; HERMANN, W. Modelagem matemática no ensino de matemática: uma estratégia para o ensino envolvendo o consumo racional de água. In: PARANÁ. Secretaria de Estado da Educação. Superintendência de Educação. Os desafios da escola pública paranaense na perspectiva do professor PDE. Curitiba: SEED/PR, 2014a. v. 1. (Cadernos PDE). p. 2-18. Disponível em: http://www.diaadiaeducacao.pr.gov.br/ portals/cadernospde/pdebusca/producoes_pde/2014/2014_unespar-campomourao_ mat_artigo_marli_candido_da_silva.pdf. Acesso em: mar. 2020.

SILVA, M. C.; HERMANN, W. Uma estratégia para o uso racional da água: desenvolvendo o senso crítico por meio da Modelagem Matemática. In: PARANÁ. Secretaria de Estado da Educação. Superintendência de Educação. Os desafios da escola pública paranaense na perspectiva do professor PDE. Curitiba: SEED/PR, 2014b. v. 2. (Cadernos PDE). Disponível em: http://www.diaadiaeducacao.pr.gov.br/ portals/cadernospde/pdebusca/producoes_pde/2014/2014_unespar-campomourao_ mat_pdp_marli_candido_da_silva.pdf. Acesso em: mar. 2020.

SKOVSMOSE, O. Competência democrática e conhecimento reflexivo em matemática. For the Learning of Mathematics, v. 12, n. 2, p. 1-24, jun. 1992.

SKOVSMOSE, O. Cenários para investigação. Bolema, Rio Claro, v. 13, n. 14, p. 6691,2000.

SKOVSMOSE, O. Educação matemática crítica: a questão da democracia. 6. ed. Campinas: Papirus, 2001.

SKOVSMOSE, O. Desafios da reflexão em educação matemática crítica. Campinas: Papirus, 2008. 
SKOVSMOSE, O. O que poderia significar a educação matemática crítica para diferentes grupos de estudantes? Revista Paranaense de Educação Matemática, Campo Mourão, v. 6, n. 12, p. 18-37, 2017.

TONÁ, G. C. B.; CEOLIM, A. J. Melhorias na quadra de esportes: a modelagem matemática na perspectiva da educação matemática crítica. In: PARANÁ. Secretaria de Estado da Educação. Superintendência de Educação. Os desafios da escola pública paranaense na perspectiva do professor PDE: produções didático-pedagógicas. Curitiba: SEED/PR, 2016.v. 2. (Cadernos PDE). p. 2-39. Disponível em: http://www. diaadiaeducacao.pr.gov.br/portals/cadernospde/pdebusca/producoes_pde/2016/2016_ pdp_mat_unespar-campomourao_glauciacristhianebiacatona.pdf. Acesso em: mar. 2020. TONÁ E SILVA, G. C. B.; CEOLIM, A. J. Modelagem matemática na perspectiva da educação matemática crítica: melhorias na quadra de esportes. In: PARANÁ. Secretaria de Estado da Educação. Superintendência de Educação. Os desafios da escola pública paranaense na perspectiva do professor PDE. Curitiba: SEED/PR, 2016.v.1. (Cadernos PDE). p. 2-19. Disponível em: http://www.diaadiaeducacao.pr.gov. br/portals/cadernospde/pdebusca/producoes_pde/2016/2016_artigo_mat_unesparcampomourao_glauciacristhianebiacatona.pdf. Acesso em: mar. 2020.

ZORZANELO, M.M. Consumo abusivo de bebidas alcoólicas por adolescentes: uma proposta para a educação estatística por meio da modelagem matemática. In: PARANÁ. Secretaria de Estado da Educação. Superintendência de Educação. O professor PDE e os desafios da escola pública paranaense: produção didático-pedagógica. Curitiba: SEED/PR, 2012.v.2. (Cadernos PDE).p.2-31. Disponível em: http://www. diaadiaeducacao.pr.gov.br/portals/cadernospde/pdebusca/producoes_pde/2012/2012_ fecilcam_mat_pdp_marluce_mosoli.pdf. Acesso em: mar. 2020.

ZORZANELO, M. M.; HERMANN, W. Consumo abusivo de bebidas alcoólicas por adolescentes: uma proposta para a educação estatística por meio da modelagem matemática. In: PARANÁ. Secretaria de Estado da Educação. Superintendência de Educação. O professor PDE e os desafios da escola pública paranaense. Curitiba: SEED/PR, 2012. v. 1. (Cadernos PDE). p. 2-19. Disponível em: http://www. diaadiaeducacao.pr.gov.br/portals/cadernospde/pdebusca/producoes_pde/2012/2012 fecilcam_mat_artigo_marluce_mosoli.pdf. Acesso em: mar. 2020.

\section{SOBRE OS AUTORES}

Milene Nagila Mesquita é licenciada em matemática pela Universidade Estadual do Paraná (Unespar).

E-mail:mmvocal@hotmail.com

Amauri Jersi Ceolim é doutor em educação pela Universidade Federal de São Carlos (UFSCar). Professor da Universidade Estadual do Paraná (Unespar).

E-mail: amauri.ceolim@unespar.edu.br 
Rosefran Adriano Gonçales Cibotto é doutor em educação pela Universidade Federal de São Carlos (UFSCar). Professor da Universidade Estadual do Paraná (Unespar).

E-mail: rosefran.cibotto@unespar.edu.br

Conflitos de interesse: Os autores declaram que não possuem nenhum interesse comercial ou associativo que represente conflito de interesses em relação ao manuscrito.

Financiamento: $\mathrm{O}$ estudo não recebeu financiamento.

Contribuiçães dos autores: Administração do Projeto, Análise Formal, Conceituação, Curadoria de Dados, Escrita - Primeira Redação, Escrita - Revisão e Edição, Investigação, Metodologia, Supervisão, Validação e Visualização: Mesquita, M.N.; Ceolim, A.J.; Cibotto, R.A.G.

Recebido em 28 de abril de 2020 Aprovado em 18 de agosto de 2020 